\title{
OS PREFEITOS ATENDEM ÀS EXIGÊNCIAS LEGAIS DE PRESTAÇÃO DE CONTAS? UM OLHAR A PARTIR DOS PORTAIS ELETRÔNICOS DE MUNICÍPIOS DE SANTA CATARINA
}

\author{
Fabiano Maury Raupp ${ }^{1}$, Eliza de Abreu ${ }^{1}$, Manuella Santos Silva ${ }^{1}$ \\ Universidade do Estado de Santa Catarina ${ }^{1}$ \\ fabianoraupp@hotmail.com, elizafabreu@gmail.com, manuellasantossilva2@gmail.com
}

\section{Resumo}

O objetivo da pesquisa consiste em investigar a capacidade dos portais eletrônicos de prefeituras de municípios de Santa Catarina com população superior a 10.000 habitantes para a construção de prestação de contas. Trata-se de uma pesquisa descritiva, realizada por meio de um estudo survey, com abordagem quali-quantitativa. As observações para verificar a prestação de contas nos portais eletrônicos ocorreram em outubro e novembro de 2013. A coleta de dados foi realizada através do protocolo de observação fundamentado no modelo de análise proposto por Raupp (2011), que considera indicadores agrupados em quatro categorias: nula capacidade, baixa capacidade, média capacidade e alta capacidade. Dos 122 portais pesquisados, $90,16 \%$ apresentaram divulgação parcial e/ou total após o prazo do conjunto de exigências legais sobre os gastos incorridos, demonstrando o descumprimento da legislação. A divulgação, no prazo, do conjunto de exigências legais sobre os gastos incorridos, é realizada por $9,84 \%$ do universo pesquisado.

Palavras-chave: Prestação de Contas. Portais Eletrônicos. Municípios.

\section{DO THE MAYOR'S FULFIL THE LEGAL ACCOUNTABILITY REQUIREMENTS? A STUDY FROM THE WEB PORTALS OF SANTA CATARINA'S CITIES}

\begin{abstract}
The goal of this research is to investigate the capacity of the web portals of Santa Catarina cities with population over 10,000 inhabitants to do accountability. This is a descriptive study, conducted through a survey with qualitative and quantitative approach. The observations to verify the accountability in web portals were performed in October and November 2013. Data collection was performed through the observation protocol based on the analytical model proposed by Raupp (2011), which considers indicators grouped into four categories: zero capacity, low capacity, medium capacity and high capacity. Of the 122 web portals analyzed, $90.16 \%$ had partial and/or total disclosure after the deadline of the set of legal requirements on the expenses incurred, showing evidences of no compliance to the legislation. The disclosure on time is performed by $9.84 \%$ of the sample studied.
\end{abstract}

Keywords: Accountability. Web Portals. Municipalities.

\section{Introdução}

É notória a forma como a Tecnologia da Informação e Comunicação (TIC) tem impactado ininterruptamente a sociedade contemporânea. A disseminação das tecnologias ocorre rapidamente, e os diferentes setores, como é o caso do setor público, precisam implementar instrumentos a fim de que a gestão possa acompanhar os avanços ocorridos. Medeiros (2004) 
afirma que os governos dos países operam em um mundo complexo e é necessário que estes se adaptem as novas realidades, principalmente no que tange a globalização. Tem-se verificado a necessidade da implementação e desenvolvimento do chamado governo eletrônico, o qual permite, entre tantos fatores, uma aproximação entre os cidadãos e o governo, muitas vezes operacionalizados por meio de portais eletrônicos.

Arato (2010) afirma que novas tecnologias permitem maior flexibilidade, transparência e acessibilidade entre o Estado e a sociedade, o que é fundamental para uma maior transparência dos atos públicos. Assim, é possível verificar as prioridades de um governo, as políticas desenvolvidas e avaliar o uso dos recursos públicos. Do ponto de vista legal, os avanços também ocorreram, e a publicação da Lei de Acesso à Informação (BRASIL, 2011) reforçou a exigência de prestação de contas, por partes dos administradores públicos, já contida no texto da Lei de Responsabilidade Fiscal (BRASIL, 2000) e da Lei da Transparência (BRASIL, 2009).

A prestação de contas deve englobar, além da exigência legal, também uma etapa mais avançada de análise, na qual se deve verificar a disponibilidade de informações sobre as contas públicas, bem como justificativas, pơr parte da administração, das contas apresentadas (PRADO, 2004). Pinho (2006) afirma que é através de prestações de conta confiáveis por parte dos governantes que se atinge a accountability plena. Freire, Casto e Forte (2009) afirmam que é fundamental que se observe a acessibilidade em conteúdos disponíveis nos sítios públicos e governamentais na web para garantir acesso participativo e universal do cidadão brasileiro ao conhecimento, independente de deficiências ou qualquer outra barreira.

Neste contexto, tem-se como objeto de estudo os portais eletrônicos de prefeituras de Santa Catarina com população superior a 10.000 habitantes A pesquisa empírica parte da formulação da seguinte questão-problema: Qual o atendimento às exigências legais de prestação de contas pelas prefeituras de municípios de Santa Catarina por meio dos portais eletrônicos?

$\mathrm{O}$ objetivo da pesquisa consistiu em investigar o atendimento às exigências legais de prestação de contas pelas prefeituras de municípios de Santa Catarina com população superior a 10.000 habitantes por meio dos portais eletrônicos. Para tanto, primeiramente são apresentados os fundamentos teóricos que se julgam necessários à sustentação do objeto de investigação. Após, descreve-se os procedimentos metodológicos adotados. A próxima seção contempla os resultados alcançados. Em seguida, abre-se espaço para as conclusões do estudo.

\section{Fundamentos Teóricos}

\subsection{Accountability}

De acordo com Lopes e Freire (2010, p.72-73), “accountability é um termo anglo-saxônico, sem tradução exata para o português, mas que remete à obrigatoriedade de membros dos órgãos administrativos a prestarem contas dos gastos públicos aos cidadãos". É dever dos agentes estatais de prestarem contas e justificarem à sociedade o uso que fazem dos bens públicos. Segundo Campos (1990) o termo accountability não pode ser completamente traduzido para o português, já que não há uma cobrança por parte da sociedade civil, uma vez que existe uma falta de relação entre o Estado e a população.

O’Donnell (1991) justificou a complexidade da tradução de accountability baseando-se no fato de que o processo de transição para democracia da maioria dos países da América Latina (inclui-se o Brasil) foi conduzido para o que se chama de democracia delegativa, e não representativa. Na democracia delegativa, os representantes são eleitos por meio de eleições, mas seu mandato será da forma que achar conveniente. Para o autor, na democracia delegativa não há nenhum tipo de obrigatoriedade na prestação de contas. Pinho $(2008$, p.478) reforça a 
ideia entendendo que a "distinção entre esses dois tipos de democracia encontra-se na accountability: fraca (ou inexistente), nas democracias delegativas, e consolidada nas democracias representativas estáveis".

Em termos conceituais, Loureiro e Abrucio (2004, p.52) entendem por "accountability ou responsabilização um processo institucionalizado de controle político estendido no tempo (eleição e mandato) e no qual devem participar, de um modo ou de outro, os cidadãos organizados politicamente". Deve, portanto, ocorrer a participação constante da sociedade, mas para isso é importante estar enraizado na sociedade a prática de requerer justificativas para as ações governamentais. Assim, a accountabilitypoderá ser efetiva no que tange a cobrança pela prestação de contas e a sociedade tenha acesso ao uso que se faz dos bens públicos. De maneira aproximativa, Akutsu e Pinho (2002, p.731) defendem que a accountability tem sua ocorrência em duas partes "a primeira delega responsabilidade para que a segunda proceda à gestão dos recursos; ao mesmo tempo, gera a obrigação daquele que administra os recursos de prestar contas de sua gestão, demonstrando o bom uso desses recursos".

Pinho e Sacramento (2009, p.1364) ao 64 realizarem um estudo aprofundado do significado do termo accountability constataram que o termo poder-se-ia contemplar vários elementos: "responsabilidade (objetiva e subjetiva), controle, transparência, obrigação de prestação de contas, justificativas para as ações que foram ou deixaram de ser empreendidas, premiação e/ou castigo". Apesar da amplitude do termo, percebe-se que os diferentes elementos contemplados expressam a necessidade de "disponibilidade de informações sobre a atuação dos governos e seus resultados, bem como a existência de instituições que permitam contestar as ações do poder público" (PÓ e ABRÚCIO, 2006, p.686).

\title{
2.2 Prestação de contas
}

O termo accountability explicitado no tópico anterior abrange, segundo Campos (1990), a ideia de "transparência" nas ações conduzidas, por meio da publicação de informações; "prestação de contas" a partir dos recursos públicos no qual se fez uso e remete a ideia de obrigatoriedade para com a sociedade; e, "responsabilização" pelas ações ou omissões dos gestores públicos. Particularmente em relação à prestação de contas, em termos legais, de acordo com o parágrafo único do art. 70 da Constituição Federal (BRASIL, 1988),

\begin{abstract}
prestará contas qualquer pessoa física ou jurídica, pública ou privada que utilize, arrecade, guarde, gerencie ou administre dinheiros, bens e valores públicos, ou pelos quais a União responda, ou que, em nome desta, assuma obrigações de natureza pecuniária.
\end{abstract}

Observa-se uma sucessão de legislações que explicitam os instrumentos que deverão ser disponibilizados pelos diferentes órgãos públicos como forma de prestação de contas, com destaque para a Lei Complementar $\mathrm{n}^{\circ} 101$, de 4 de maio de 2000 (Lei de Responsabilidade Fiscal), Lei Complementar $n^{\circ} 131$, de 27 de maio de 2009 (Lei da Transparência), e Lei n $^{\circ}$ 12.527, de 18 de novembro de 2011 (Lei de Acesso à Informação). No Quadro 1 são identificados tais instrumentos de acordo com a respectiva legislação.

\begin{tabular}{|c|l|}
\hline Leis & \multicolumn{1}{c|}{ Instrumentos de prestação de contas } \\
\hline Lei Complementar & $\bullet$ planos, orçamentos e leis de diretrizes orçamentárias; \\
$\mathrm{n}^{\text {o } 101 \text {, de 4 de maio }}$ & - prestações de contas e o respectivo parecer prévio; \\
de 2000 (LRF) & - Relatório Resumido da Execução Orçamentária; \\
\hline
\end{tabular}




\begin{tabular}{|c|c|}
\hline $\begin{array}{l}\text { Lei Complementar } \\
\text { n }^{\circ} 131, \text { de } 27 \text { de } \\
\text { maio de } 2009 \text { (Lei } \\
\text { da Transparência) }\end{array}$ & $\begin{array}{l}\text { - quanto à despesa: todos os atos praticados pelas unidades gestoras no decorrer da } \\
\text { execução da despesa, no momento de sua realização, com a disponibilização mínima } \\
\text { dos dados referentes ao número do correspondente processo, ao bem fornecido ou ao } \\
\text { serviço prestado, à pessoa física ou jurídica beneficiária do pagamento e, quando for o } \\
\text { caso, ao procedimento licitatório realizado; } \\
\text { - quanto à receita: o lançamento e o recebimento de toda a receita das unidades } \\
\text { gestoras, inclusive referente a recursos extraordinários. }\end{array}$ \\
\hline $\begin{array}{l}\text { Lei } n^{\circ} 12.527 \text {, de } 18 \\
\text { de novembro de } \\
2011 \text { (Lei de Acesso } \\
\text { à Informação) }\end{array}$ & $\begin{array}{l}\text { - registros de quaisquer repasses ou transferências de recursos financeiros; } \\
\text { - registros das despesas; } \\
\text { - informações concernentes a procedimentos licitatórios, inclusive os respectivos } \\
\text { editais e resultados, bem como a todos os contratos celebrados; } \\
\text { - dados gerais para o acompanhamento de programas, ações, projetos e obras de órgãos } \\
\text { e entidades. }\end{array}$ \\
\hline
\end{tabular}

Quadro 1 - Instrumentos de prestação de contas (Adaptado de BRASIL, 2000; BRASIL, 2009; BRASIL, 2011)

Percebe-se, a partir do Quadro 1, a existência de normas que resguardam à obrigatoriedade dos administradores públicos em prestare contas à sociedade dos gastos incorridos. Platt Neto et al. (2007) evidenciam que há diversas estratégias de divulgação das contas públicas, podendo uma estratégia contribuir para amenizar as limitações das outras. Cabe mencionar que as legislações (BRASIL, 2000; BRASIL, 2009; BRASIL, 2011) já mencionadas, dão destaque para os meios eletrônicos, como pode ser observado no Quadro 2.

\begin{tabular}{|c|c|}
\hline Leis & Menção ao uso de meios eletrônicos \\
\hline $\begin{array}{l}\text { Lei Complementar } \mathrm{n}^{\circ} 101 \text {, de } 4 \text { de } \\
\text { maio de } 2000(\mathrm{LRF})\end{array}$ & $\begin{array}{l}\text { Aos instrumentos "será dada ampla divulgação, inclusive em meios } \\
\text { eletrônicos de acesso público." (art. 48) }\end{array}$ \\
\hline $\begin{array}{l}\text { Lei Complementar } \mathrm{n}^{\circ} 131 \text {, de } 27 \text { de } \\
\text { maio de } 2009 \text { (Lei da Transparência) }\end{array}$ & $\begin{array}{l}\text { "Liberação ao pleno conhecimento e acompanhamento da sociedade, em } \\
\text { tempo real, de informações pormenorizadas sobre a execução } \\
\text { orçamentária e financeira, em meios eletrônicos de acesso público." (II, } \\
\text { parágrafo único, art. 48) }\end{array}$ \\
\hline $\begin{array}{l}\text { Lei } n^{\circ} 12.527 \text {, de } 18 \text { de novembro de } \\
2011 \text { (Lei de Acesso à Informação) }\end{array}$ & $\begin{array}{l}\text { "os órgãos e entidades públicas deverão utilizar todos os meios e } \\
\text { instrumentos legítimos de que dispuserem, sendo obrigatória a } \\
\text { divulgação em sítios oficiais da rede mundial de computadores } \\
\text { (internet)". ( }\left(2^{\circ} \text {, art. } 8^{\circ}\right)\end{array}$ \\
\hline
\end{tabular}

Quadro 2 - Menção ao uso de meios eletrônicos (Adaptado de BRASIL, 2000; BRASIL, 2009; BRASIL, 2011)

O conteúdo do Quadro 2 torna explícita a obrigatoriedade no uso de meios eletrônicos para publicização dos instrumentos evidenciados no Quadro 1 e, consequentemente, para o exercício da prestação de contas. O uso de meios eletrônicos, por sua vez, está "conectado" ao conceito do chamado governo eletrônico, que, apesar de apresentar perspectivas mais amplas, pode contribuir para o atendimento das exigências legais.

\subsection{Governo eletrônico}

É evidente a revolução da informação ocorrida nas últimas décadas e as mudanças drásticas que essa acarretou na forma de as pessoas se relacionarem. Destaca-se na tecnologia da informação e comunicação (TIC) a internet que proporcionou ao governo possibilidades maiores para a abertura de relacionamentos com a sociedade. Nessas circunstâncias, em que o mundo empresarial sofreu alterações com o advento da Sociedade da Informação, surgiu o que se denomina de governo eletrônico ou e-gov. "O e-gov representa, de uma maneira mais visível, o provimento de acesso público via Internet a informações sobre os serviços oferecidos pelos departamentos centrais do governo e suas agências, habilitando o público à condução e conclusão de transações para tais serviços" (NATIONAL AUDIT OFFICE, 2002, p.10). Deste modo, “o Estado, por intermédio do governo eletrônico, é o principal instrumento 
de que os cidadãos dispõem atualmente para enfrentar os desafios impostos pela globalização, por meio de interações inéditas da sociedade,empresas e governos" (BRAGA et al, 2008, p.5).

O governo eletrônico é um "potencializador de boas práticas de governança e catalisador de uma mudança profunda nas estruturas de governo, proporcionando mais eficiência, transparência e desenvolvimento, além do provimento democrático de informações para decisão" (RUEDGER, 2002, p.30). Mas, "mais do que um provedor de serviços online, poderá ser, sobretudo, uma ferramenta de capacitação política da sociedade" (RUEDGER, 2002, p.26).

Ribeiro Filho, Campelo e Araújo $(2005$, p.4) entendem que "o governo eletrônico é uma consequência da globalização e do desenvolvimento da tecnologia, com uma dimensão social importante, em virtude do seu potencial de reduzir distâncias, promovendo a integração entre as pessoas e disseminando informação para todos". Já de acordo com Pinho (2008), embora exista muita tecnologia, existe o problema da cultura política brasileira que pode acarretar no desenvolvimento desacelerado desta. $\mathrm{O}$ autor faz uma ressalva de que o governo eletrônico foi uma ampliação de possibilidades de interação entre o Estado e os cidadãos, uma vez que"as TICs contêm um enorme potencial democratico, desde que haja definição política no sentido da participação popular e da transparência, pois o governo pode deixar de oferecer o que não quer mostrar, para nem mencionar o que quer esconder" (PINHO, 2008, p.475).

Além disso, vale ressaltar que no mundo contemporâneo, "o uso da world wide web (web) para disponibilização de informações para os cidadãos nas diversas esferas da administração pública tem se ampliado com enorme rapidez" (FREIRE, CASTRO, FORTES, 2009, p.396). E, por conta dessa ampliação, surgiram instrumentos para operacionalizar o governo eletrônico, por exemplo, osportais eletrônicos.Os portais, por sua vez, para Pinho (2006, p.1) "representam um componente fundamental da sociedade de informação e do avanço vertiginoso das Tecnologias de Informação e Comunicação (TIC) na sociedade contemporânea" isso porque, o acesso à informação via web se tornou mais fácil. Cunha (2000, p.1) define

\footnotetext{
um portal é uma porta de entrada na rede mundial. É a partir do portal que muitos usuários definem seus próximos passos na Web. Os portais são locais de grande visitação, portanto ser reconhecido como um portal está diretamente relacionado à força com que o site atrai visitantes. Os serviços mais comuns de um portal incluem serviços de e-mail, bate-papo (chat), serviços de busca e serviços de notícias, gratuitos ou não.
}

Pinho (2006, p.3) destaca que "um portal é uma página na Internet a partir do qual todos os serviços e informações da entidade podem ser acessados. É ainda um canal de comunicaçãoentre governos e cidadãos que possibilita a estes exercitar a cidadania e aperfeiçoar a democracia". Através dos portais eletrônicos, as informações podem ser disponibilizadas aos cidadãos. Além dessa disponibilidade, Freire, Castro e Fortes (2009) argumentam que "nesse quesito, a acessibilidade se apresenta como um aspecto essencial para promover a inclusão na sociedade da informação". A partir dos portais, os governos explicitam suas intenções e fornecem informações aos cidadãos impulsionandoa prestação de contas e a transparência e, consequentemente, a accountability (PINHO, 2006).

\section{Procedimentos Metodológicos Adotados}

As tipologias de pesquisa foram consideradas quanto aos objetivos, quanto aos procedimentos e quanto à abordagem do problema. No tocante à tipologia relacionada aos objetivos, trata-se de uma pesquisa descritiva. No que concerne aos procedimentos, refere-se a um estudo survey. Quanto à abordagem do problema, o estudo utilizou a abordagem quali-quantitativa.

Quanto à população, o objeto de estudo refere-se aos portais eletrônicos de Prefeituras de 
Municípios do Estado de Santa Catarina com população superior a 10.000 habitantes. A opção por este porte populacional deve-se ao $\S 4^{\circ}$, art. $8^{\circ}$, da Lei de Acesso à Informação, que define: "os municípios com população de até 10.000 (dez mil) habitantes ficam dispensados da divulgação obrigatória na internet a que se refere o $\S 2^{0}$, mantida a obrigatoriedade de divulgação, em tempo real, de informações relativas à execução orçamentária e financeira" (BRASIL, 2011).O Estado de Santa Catarina é formado por 295 municípios, dos quais 122 possuem população superior a 10.000 habitantes. A identificação dos endereços dos portais eletrônicos foi realizada por meio de uma busca no site Google no dia 23 de março de 2013.

As observações para verificar a prestação de contas nos portais eletrônicos das prefeituras ocorreram em outubro e novembro de 2013. A coleta de dados foi realizada por meio do protocolo de observação (CRESWELL, 2007). O protocolo fundamentou-se no modelo de análise proposto por Raupp (2011), cujos indicadores foram agrupados em quatro categorias: nula capacidade, baixa capacidade, média capacidade e alta capacidade. Procurou-se verificar a capacidade dos portais de executivos municipais em construir a prestação de contas por meio do modelo de análise apresentado no Quadro 3.

\begin{tabular}{|c|l|}
\hline Capacidade & \multicolumn{1}{c|}{ Indicadores } \\
\hline Nula & Inexistência de indicadores de prestação contas e/ou impossibilidade de sua localização \\
\hline Baixa & Divulgação parcial e/ou após o prazo do conjunto de exigências legais sobre os gastos incorridos \\
\hline Média & Divulgação, no prazo, do conjunto de exigências legais sobre os gastos incorridos \\
\hline Alta & Divulgação, além do conjunto de exigências legais no prazo, de relatórios complementares \\
\hline
\end{tabular}

Quadro 3 - Modelo de análise (RAUPP, 2011)

O modelo proposto por Raupp (2011) considera com nula capacidade o portal no qual seja observada a inexistência de indicadores de prestação contas e/ou impossibilidade de sua localização. Em caso de divulgação parcial e/ou após o prazo do conjunto de exigências legais sobre os gastos incorridos, o portal eletrônico apresenta baixa capacidade em prestar contas. A média capacidade do portal será indicada a partir da divulgação, no prazo, do conjunto de exigências legais sobre os gastos incorridos. A alta capacidade do portal será identificada quando houve divulgação, além do conjunto de exigências legais no prazo, de relatórios complementares dos gastos incorridos.

A análise da capacidade dos portais (nula, baixa, média ou alta) contemplou diferentes elementos, dos quais alguns merecem esclarecimentos: prazo de divulgação, forma de apresentação, e detalhamento das informações. Em relação ao prazo, cabe ressaltar que há exigências legais (Quadro 1) com periodicidades diferentes, por exemplo, há relatórios que devem ser publicizados anualmente, outros semestralmente, quadrimestralmente, bimestralmente ou mesmo diariamente. Contudo, considerando que as informações poderiam ser inseridas posteriormente, mas com data anterior, tomou-se como referência o período de coleta de dados (outubro e novembro de 2013), a fim de verificar se, por exemplo, os relatórios referentes ao último bimestre/quadrimestre estavam disponibilizados. Em relação aos dados de divulgação diária, buscou-se identificar informações recentes. Deve-se mencionar que há elementos do Quadro 1 que, mesmo não sendo identificados, não prejudicaram a classificação dos portais. Um exemplo disso diz respeito às informações sobre licitações, pois, se não há processos de licitação tramitando no momento, consequetemente não há informações disponíveis nos portais. Já para os municípios de maior porte (acima de 50.000 habitantes), o pressuposto foi de que deveriam existir informações atuais sobre licitação em razão da necessidade constante de compras e do próprio valor das compras.

No tocante à forma de apresentação, foi considerado que há informações que devem seguir padrões regulamentos e que há informações que não precisam seguir padrões, podendo ser identificadas nos portais em diferentes formatos. Por último, infere-se que o Quadro 1 apresenta os grupos de informações, porém, não evidencia o detalhamento inerente à 
determinados grupos. Um exemplo desse detalhamento refere-se à folha de pagamento invidualizada, que, apesar de não estar contemplada no Quadro 1, foi considerada à medida que as visitas aos portais eram realizadas.

\section{Resultados}

Os portais dos municípios pesquisados foram agrupados de acordo com suas faixas populacionais nas seguintes classes: municípios de 10.001 a 20.000 habitantes; 20.001 a 50.000 habitantes; 50.001 a 100.000 habitantes; 100.001 a 500.000. Sendo que Joinville é o único que apresenta uma população maior que 500.000 habitantes, mas foi considerado no agrupamento da classe populacional de 100.001 a 500.000 habitantes. A opção pela apresentação dos resultados baseada no tamanho populacional levou em consideração três razões colocadas por Raupp e Pinho (2013): a divisão da análise em classes de população considera as faixas de tamanho da população dos municípios brasileiros, definidas pelo Instituto Brasileiro de Geografia e Estatística; há a expectativa de que à medida que a população cresce aumentam as condiçõe humanos para construir os portais; municípios de um mesmo grupo populacionaldevem ter mais homogeneidade, gerando resultados mais próximos.

\subsection{Prestação de contas nos portais eletrônicos de 10.001 a 20.000 habitantes}

A primeira classe populacional corresponde aos municípios de 10.001 a 20.000 habitantes. Os resultados das observações nestes portais eletrônicos foram sintetizados na Tabela 1.

\begin{tabular}{|c|c|c|}
\hline$N$. & Município & Prestação de contas \\
\hline 1 & Abelardo Luz & baixa \\
\hline 2 & Balneário Piçarras & baixa \\
\hline 3 & Balneário Rincão & baixa \\
\hline 4 & Benedito Novo & baixa \\
\hline 5 & Bombinhas & baixa \\
\hline 6 & Campo Alegre & baixa \\
\hline 7 & Canelinha & baixa \\
\hline 8 & Cocal do Sul & baixa \\
\hline 9 & Coronel Freitas & baixa \\
\hline 10 & Correia Pinto & baixa \\
\hline 11 & Corupá & baixa \\
\hline 12 & Cunha Porã & baixa \\
\hline 13 & Dionísio Cerqueira & baixa \\
\hline 14 & Faxinal dos Guedes & baixa \\
\hline 15 & Garopaba & baixa \\
\hline 16 & Garuva & baixa \\
\hline 17 & Governador Celso Ramos & baixa \\
\hline 18 & Gravatal & baixa \\
\hline 19 & Guabiruba & baixa \\
\hline 20 & Guaraciaba & baixa \\
\hline 21 & Ibirama & baixa \\
\hline 22 & Ilhota & baixa \\
\hline 23 & Imaruí & baixa \\
\hline 24 & Irineópolis & baixa \\
\hline 25 & Itapiranga & baixa \\
\hline 26 & Itapoá & média \\
\hline 27 & Jacinto Machado & baixa \\
\hline 28 & Jaguaruna & baixa \\
\hline 29 & Lauro Muller & baixa \\
\hline 30 & Lebon Régis & baixa \\
\hline
\end{tabular}




\begin{tabular}{|c|c|c|}
\hline 31 & Lontras & baixa \\
\hline 32 & Luiz Alves & baixa \\
\hline 33 & Massaranduba & média \\
\hline 34 & Mondaí & baixa \\
\hline 35 & Morro da Fumaça & baixa \\
\hline 36 & Nova Trento & baixa \\
\hline 37 & Nova Veneza & baixa \\
\hline 38 & Otacílio Costa & baixa \\
\hline 39 & Palmitos & baixa \\
\hline 40 & Papanduva & baixa \\
\hline 41 & Pinhalzinho & baixa \\
\hline 42 & Ponte Serrada & baixa \\
\hline 43 & Porto Belo & baixa \\
\hline 44 & Pouso Redondo & média \\
\hline 45 & Presidente Getúlio & baixa \\
\hline 46 & Quilombo & baixa \\
\hline 47 & Rio dos Cedros & baixa \\
\hline 48 & Rodeio & baixa \\
\hline 49 & Sangão & baixa \\
\hline 50 & Santa Cecília & baixa \\
\hline 51 & Santo Amaro do Imperatriz & baixa \\
\hline 52 & São Carlos & baixa \\
\hline 53 & São José do Cedro & baixa \\
\hline 54 & São Ludgero & baixa \\
\hline 55 & Schroeder & média \\
\hline 56 & Seara & baixa \\
\hline 57 & Siderópolis & baixa \\
\hline 58 & Taió & baixa \\
\hline 59 & Três Barras & baixa \\
\hline 60 & Turvo & baixa \\
\hline 61 & Urubici & baixa \\
\hline
\end{tabular}

Tabela 1 - Prestação de contas nos portais eletrônicos de prefeituras em municípios de 10.001 a 20.000 habitantes (Dados da pesquisa)

De acordo com a Tabela 1 pode-se perceber que os municípios enquadrados nesta classe populacional apresentam em sua maioria capacidade baixa na prestação de contas, pois divulgam de forma parcial e/ou após o prazo o conjunto de exigências legais sobre os gastos incorridos.Os extremos não foram observados, haja vista a ausência de portais com capacidade nula e alta, ou seja, nenhum destes municípios apresentouinexistência de indicadores de prestação contas e/ou impossibilidade de sua localização, mas também não divulgam, além do conjunto de exigências legais no prazo, relatórios complementares.

Apenas $6,56 \%$ dos portais desta classe populacional apresentaram capacidade média, pois atendem à totalidade das exigências (BRASIL, 2000; BRASIL, 2009; BRASIL, 2011). É perceptível o descaso em relação aos dispositivos legais, já que 93,44\% dos portais pesquisados têm baixa capacidade. Cabe lembrar aqui a idade da LRF que, mesmo tendo aproximadamente treze anos, ainda é desconsiderada pela maioria dos municípios desta classe populacional. Em relação ao que determina a Lei da Transparência, o prazo para atendimento das exigências pelos municípios com população de até 50.000 habitantes terminou em maio de 2013, cinco meses antes do início da coleta de dados. A Lei de Acesso à Informação, sendo também descumprida pelos municípios, não menciona prazos para adequação por parte dos órgãos públicos, talvez pelo fato da Lei da Transparência já definir prazos.

\subsection{Prestação de contas nos portais eletrônicos de 20.001 a 50.000 habitantes}

Dos acessos aos portais dos municípios situados na classe populacional de 20.001 a 50.000 
habitantes resultaram as capacidades identificadas na Tabela 2.

\begin{tabular}{|c|c|c|}
\hline$N$. & Municipio & Prestação de contas \\
\hline 1 & Araquari & baixa \\
\hline 2 & Barra Velha & baixa \\
\hline 3 & Braço do Norte & baixa \\
\hline 4 & Campos Novos & baixa \\
\hline 5 & Capinzal & média \\
\hline 6 & Capivari de Baixo & baixa \\
\hline 7 & Curitibanos & baixa \\
\hline 8 & Forquilhinha & baixa \\
\hline 9 & Fraiburgo & baixa \\
\hline 10 & Guaramirim & baixa \\
\hline 11 & Herval d'Oeste & baixa \\
\hline 12 & Içara & baixa \\
\hline 13 & Imbituba & baixa \\
\hline 14 & Itaiópolis & baixa \\
\hline 15 & Itapema & baixa \\
\hline 16 & Ituporanga & baixa \\
\hline 17 & Joaçaba & média \\
\hline 18 & Laguna & baixa \\
\hline 19 & Maravilha & baixa \\
\hline 20 & Orleans & baixa \\
\hline 21 & Penha & baixa \\
\hline 22 & Pomerode & média \\
\hline 23 & Porto União & baixa \\
\hline 24 & Rio Negrinho & baixa \\
\hline 25 & São Francisco do Sul & baixa \\
\hline 26 & São João Batista & baixa \\
\hline 27 & São Joaquim & baixa \\
\hline 28 & São Lourenço do Oeste & baixa \\
\hline 29 & São Miguel do Oeste & baixa \\
\hline 30 & Sombrio & baixa \\
\hline 31 & Tijucas & baixa \\
\hline 32 & Timbó & baixa \\
\hline 33 & Urussanga & baixa \\
\hline 34 & Videira & baixa \\
\hline 35 & Xanxerê & baixa \\
\hline 36 & Xaxim & baixa \\
\hline
\end{tabular}

Tabela 2 - Prestação de contas nos portais eletrônicos de prefeituras em municípios de 20.001 a 50.000 habitantes (Dados da pesquisa)

Os resultados da Tabela 2 apontam que o avanço na classe populacional não é acompanhado pelo avanço na prestação de contas dos prefeitos. Na mesma linha da classe anterior, observa-se que a maioria dos municípios enquadrados na classe populacional de 20.001 a 50.000 habitantes apresentam capacidade baixa de prestação de contas. Da mesma forma, não foram observadas as ocorrências nula e alta.

Dentre os 36 municípios desta classe populacional, somente 8,33\% apresentam capacidade média na prestação de contas, e atendem às exigências legais (BRASIL, 2000; BRASIL, 2009; BRASIL, 2011). A disponibilização de instrumentos de prestação de contas (Quadro 1) varia muito entre as prefeituras. Há portais eletrônicos de fácil acesso. Há também portais cujo acesso aos links disponíveis não foi possível durante o período de observação. Em outros portais o acesso foi possível, porém, não existiam relatórios armazenados. Alguns portais são atualizados constantemente, outros estão desatualizados há algum tempo. 


\subsection{Prestação de contas nos portais eletrônicos de 50.001 a 100.000 habitantes}

A terceira classe populacional corresponde aos municípios de 50.001 a 100.000 habitantes. Os resultados das observações nestes portais eletrônicos foram sintetizados na Tabela 3.

\begin{tabular}{r|l|c}
\hline \multicolumn{1}{|c|}{ Município } & \multicolumn{1}{c}{ Prestação de contas } \\
\hline 1 & Araranguá & baixa \\
\hline 2 & Biguaçu & baixa \\
\hline 3 & Caçador & baixa \\
\hline 4 & Camboriú & baixa \\
\hline 5 & Canoinhas & média \\
\hline 6 & Concórdia & média \\
\hline 7 & Gaspar & baixa \\
\hline 8 & Indaial & baixa \\
\hline 9 & Mafra & baixa \\
\hline 10 & Navegantes & baixa \\
\hline 11 & Rio do Sul & baixa \\
\hline 12 & São Bento do Sul média \\
\hline 13 & Tubarão & baixa \\
\hline \multicolumn{2}{r}{ Tabela 3 Prestação de contas nos portais eletrônicos de prefeituras em municípios de 50.001 a 100.000 } \\
\end{tabular}

Surpreendem os resultados da Tabela 3 em razão do porte dos municípios que integram esta classe populacional. Dos 13 municípios analisados, apenas 3 atendem às exigências legais (BRASIL, 2000; BRASIL, 2009; BRASIL, 2011), representando 23,08\%, sendo que destes nenhum dos municípios apresentou capacidade alta. Como já era de se esperar, nenhum portal teve sua capacidade como nula. Contudo, seguindo a lógica das classes anteriores, a maioria dos portais teve a capacidade classificada como baixa, sendo representado por $76,92 \%$ dos portais pesquisados com a classe populacional de 50.001 a 100.000 habitantes.

\subsection{Prestação de contas nos portais eletrônicos de 100.001 a 500.000 habitantes}

A partir dos acessos aos portais dos municípios situados na classe populacional de 100.001 a 500.000 habitantes obtiveram-se as capacidades identificadas na Tabela 4. Vale ressaltar que apesar de o município de Joinville ter uma população superior a 500.000 habitantes ele foi considerado nesta classe populacional.

\begin{tabular}{r|l|c}
\hline$N$. & \multicolumn{1}{|c|}{ Municipio } & Prestação de contas \\
\hline 1 & Balneário Camboriú & baixa \\
\hline 2 & Blumenau & baixa \\
\hline 3 & Brusque & baixa \\
\hline 4 & Chapecó & baixa \\
\hline 5 & Criciúma & baixa \\
\hline 6 & Florianópolis & baixa \\
\hline 7 & Itajaí & média \\
\hline 8 & Jaraguá do Sul & baixa \\
\hline 9 & Joinville & média \\
\hline 10 & Lages & baixa \\
\hline 11 & Palhoça & baixa \\
\hline 12 & São José & baixa \\
\hline
\end{tabular}

Tabela 4 - Prestação de contas nos portais eletrônicos de prefeituras em municípios de 100.001 a 500.000 habitantes (Dados da pesquisa)

Os resultados observados na Tabela 4 acompanham uma realidade já demonstrada nas classes anteriores. Mesmo contemplando os municípios com o maior porte populacional do 
estado de Santa Catarina, incluindo até a própria capital do Estado, a maioria dos portais eletrônicos desta classe populacional tive a capacidade de prestação de contas classificada como baixa, sendo representada por $83,33 \%$ dos portais investigados nessa faixa populacional. Não foram identificados portais com capacidade nula ou alta. Verificou-se que $16,67 \%$ dos municípios disponibilizam todos os instrumentos legais de prestação de contas (BRASIL, 2000; BRASIL, 2009; BRASIL, 2011), conferindo a estes portais a classificação média.

\subsection{Síntese da prestação de contas nos portais eletrônicos}

A síntese da prestação de contas nos portais eletrônicos dos municípios de Santa Catarina com população superior a 10.000 habitantes é explicitada na Tabela 5.

\begin{tabular}{|c|c|c|c|c|c|}
\hline \multirow{2}{*}{ Classe populacional } & \multicolumn{4}{|c|}{ Capacidade } & \multirow{2}{*}{ Total } \\
\hline & Nula & Baixa & Média & Alta & \\
\hline 10.001 a 20.000 habitantes & 0 & 57 & 4 & 0 & 61 \\
\hline 20.001 a 50.000 habitantes & 0 & 33 & 3 & 0 & 36 \\
\hline 50.001 a 100.000 habitantes & 0 & 10 & 3 & 0 & 13 \\
\hline 100.001 a 500.000 habitantes & 0 & 10 & 2 & 0 & 12 \\
\hline Total & 0 & 110 & 12 & 0 & 122 \\
\hline
\end{tabular}

Tabela 5 - Síntese da prestação de contas nos portais eletrônicos (Dados da pesquisa)

A síntese apresentada na Tabela 5 sumariza a prestação de contas de municípios catarinenses com população superior a 10.000 habitantes. Do total de portais eletrônicos analisados (122), 90,16\% tiveram sua capacidade de prestação de contas classificada como baixa, indicando que a maioria dos municípios não atendem às exigências legais preconizadas na LRF (BRASIL, 2000), na Lei da Transparência (BRASIL, 2009) e na Lei de Acesso à Informação (BRASIL, 2011). Não houve municípios com capacidade nula, o que já era uma expectativa. Contudo, também não houve portais com capacidade alta, o que não era o esperado, uma vez que os municípios com maiores condições deveriam prezar mais pela efetivação da prestação de contas.

Conforme abordado no início da seção 4, a opção pela apresentação dos resultados baseada no tamanho populacional levou em consideração, dentre alguns fatores, a expectativa de que à medida que o porte populacional aumentasse, aumentariam também as condições de mais recursos tecnológicos, financeiros e humanos para construir os portais (RAUPP e PINHO, 2013). Contudo, esse pressuposto não foi confirmado no conjunto de municípios objeto de estudo, pois o aumento no porte populacional não foi acompanhado pela evolução na prestação de contas.

\section{Considerações Finais}

O artigo teve como objetivo investigar a prestação de contas realizada nos portais eletrônicos dos municípios de Santa Catarina com população superior a 10.000 habitantes. Dos 122 portais pesquisados, $90,16 \%$ apresentaram divulgação parcial e/ou após o prazo do conjunto de exigências legais sobre os gastos incorridos, demonstrando o descumprimento da legislação. A divulgação, no prazo, do conjunto de exigências legais sobre os gastos incorridos, é realizada por $9,84 \%$ do universo pesquisado. Dessa maneira, os portais eletrônicos estão atuando como uma ferramenta de capacitação política da sociedade (RUEDGER, 2002).

Os extremos, ou seja, portais com capacidade nula ou alta, não foram protagonistas do conjunto de resultados. Tal constatação pode indicar, simultaneamente, aspectos positivos e negativos. O aspecto positivo fica por conta de uma possível busca dos municípios em atender 
às exigências legais. $\mathrm{O}$ aspecto negativo refere-se a ausência de experiências que buscassem ir além das exigências legais, demonstrando o exercício avançado da prestação de contas (PRADO, 2004). Porém, acredita-se que a ausência de portais com capacidade alta seja também reflexo de número reduzido de portais com capacidade média pois, conforme definido no Modelo de Análise, a alta capacidade do portal seria identificada quando houvesse divulgação, além do conjunto de exigências legais no prazo, de relatórios complementares dos gastos incorridos. Portanto, os portais governamentais realmente não estão sendo considerados como porta de entrada do governo eletrônico, oferecendo informações e facilidade de serviços para a população, incrementando assim a sua accountability, prestando contas e sendo transparente com a socidade (PINHO, 2006).

Como resposta à indagação feita no próprio título, contata-se que os prefeitos não atendem às exigências legais de prestação de contas (BRASIL, 2000; BRASIL, 2009; BRASIL, 2011). Como sanções previstas no inciso I do $\S 3^{-0}$ do art. 23, da Lei de Responsabilidade Fiscal, em caso de descumprimento, o ente não poderá: "I - receber transferências voluntárias; II - obter garantia, direta ou indireta, de outro ente; III - contratar operações de crédito, ressalvadas as destinadas ao refinanciamento da dívida mobiliária e as que visem à redução das despesas com pessoal" (BRASIL, 2000; BRASIL, 2009). Se a lei não é cumprida mesmo existindo sanções, ou é cumprida minimamente, os executivos municipais podem estar na posição de aguardo para ver "se a lei vai pegar" realmente.

\section{Referências}

AKUTSU, Luiz; PINHO, José Antônio Gomes de. Sociedade da informação,accountabilitye democracia delegativa: investigação em portais de governo no Brasil. Revista de Administração Pública, Rio de Janeiro, ano 36, n.5, p.723-745, set./out. 2002.

BRAGA, Lamartine Vieira et al. O papel do governo eletrônico no fortalecimento da governança do setor público. Revista do Serviço Público, Brasília, DF, ano 59, n.1, p.5-21, jan./mar. 2008

BRASIL. Lei da Transparência. Lei Complementar $n^{\circ}$ 131, de 27 de Maio de 2009. Presidência da República. Casa Civil. Subchefia para Assuntos Jurídicos. Brasília, 2009.

BRASIL. Lei de Acesso a Informações Públicas. Lei n ${ }^{12.527}$, de 18 de novembro de 2011. Presidência da República. Casa Civil. Subchefia para Assuntos Jurídicos. Brasília, 2011.

BRASIL. Lei de Responsabilidade Fiscal. Lei Complementar n $^{\circ} 101$, de 04 de Maio de 2000. Presidência da República. Casa Civil. Subchefia para Assuntos Jurídicos. Brasília, 2000 .

BRASIL. PRESIDÊNCIA DA REPÚBLICA. CASA CIVIL. SUBCHEFIA PARA ASSUNTOS JURÍDICOS. Constituição da República Federativa do Brasil de 1988. Disponível em: < http://www.planalto.gov.br/ccivil_03/constituicao/constituicao.htm>. Acesso em: 19 out. 2013.

CAMPOS, Ana Maria. Accountability: quando poderemos traduzi-la para o português? Revista de Administração Pública, Rio de Janeiro, ano 24, n.2, p.30-50, fev./abr. 1990.

CARLOS, A. F. et al. Uma discussão sobre a criação de indicadores de transparência na gestão pública federal como suporte ao ciclo da política pública. Revista de Contabilidade do Mestrado em Ciências Contábeis da UERJ, Rio de Janeiro, v.13, n.2, p.1, maio/ago, 2008 . 
CRESWELL, J. W. Projeto de pesquisa: método qualitativo, quantitativo e misto. Porto Alegre: Artmed, 2007.

CUNHA, Maria Alexandra Viegas Cortez da. Portal de serviços públicos e de informação ao cidadão: estudo de casos no Brasil. 2000. 172f. Tese (Doutorado em Administração) Programa de Pós-Graduação em Administração - Faculdade de Economia, Administração e Contabilidade da Universidade de São Paulo, São Paulo, 2000.

FREIRE, André Pimenta; CASTRO, Mário de; FORTES, Renata Pontin de Mattos. Acessibilidade dos sítios web dos governos estaduais brasileiros: uma análise quantitativa entre 1996 e 2007. Revista de Administração Pública, Rio de Janeiro, ano 43, n. 2, p. 395 414, mar./abr. 2009.

LOPES, Francisco Cristiano; FREIRE, Geovana Maria Cartaxo de Arruda. Governo Eletrônico e Accountability: Avaliação da Publicização das Contas Públicas dos Estados Brasileiros. In: Encontro Nacional dö4 CONPEDI, XIX, 2010, Fortaleza. Anais... Florianópolis: CONPEDI, 2010.

LOUREIRO, Maria Rita; ABRUCIO, Fernando Luiz. Política e reformas fiscais no Brasil recente. Revista de Economia Política, São Paulo, ano 24, n.1, p.50-72, jan./mar. 2004.

MEDEIROS, Paulo Henrique Ramos. Governo Eletrônico no Brasil: Aspectos Institucionais e Reflexos na Governança. Dissertação (Mestrado em Administração). Brasília: UnB, 2004.

NATIONAL AUDIT OFFICE. Better public services through e-government. Londres: The Stationery Office, 2002.

O’DONNELL, Guillermo. Democracia delegativa? Novos Estudos, São Paulo, n.31, p.25-40, out. 1991.

PINHO, José Antonio Gomes de. Accountability em portais estaduais e municipais no Brasil: realidades distantesdas promessas. In: ENCONTRO DE ADMINISTRAÇÃO PÚBLICA E GOVERNANÇA, II, 2006, São Paulo. Anais... Rio de Janeiro: Anpad, 2006.

PINHO, José Antonio Gomes de. Investigando portais de governo eletrônico de estados no Brasil: muita tecnologia, pouca democracia. Revista de Administração Pública, Rio de Janeiro, ano 42, n.3, p.471-493, maio/jun. 2008.

PINHO, José Antonio Gomes de; SACRAMENTO, Ana Rita Silva. Accountability: já podemos traduzi-la para o português? Revista de Administração Pública, Rio de Janeiro, ano 43, n.6, p.1343-1368, nov./dez. 2009.

PLATT NETO, O. A.; CRUZ, F.; ENSSLIN, S. R; ENSSLINL. Publicidade e transparência das contas públicas: obrigatoriedade e abrangência desses princípios na administração pública brasileira. Contabilidade Vista \& Revista. Belo Horizonte, v. 18, n. 1, p. 75-94, jan./mar. 2007

PÓ, Marcos Vinicius; ABRUCIO, Fernando Luiz. Desenho e funcionamento dos mecanismos de controle e accountability das agências reguladoras brasileiras: semelhanças e diferenças. Revista de AdministraçãoPública, Rio de Janeiro, v.40, n.4, p.679-98, jul./ago. 2006. 
PRADO, O. Governo eletrônico e transparência: a publicização das contas públicas das capitais brasileiras. 2004. 180 p. Dissertação (Mestrado em Administração Pública e Governo) - EAESP - Fundação Getúlio Vargas, São Paulo, 2004.

RAUPP, Fabiano Maury. Construindo a accountability em Câmaras Municipais do Estado de Santa Catarina: uma investigação nos portais eletrônicos. 2011. 193 f. Tese (Doutorado em Administração) - Núcleo de Pós-Graduação em Administração, Universidade Federal da Bahia, Salvador, 2011.

RAUPP. Fabiano Maury; PINHO, José Antonio Gomes de. Accountability em câmaras municipais: uma investigação em portais eletrônicos. Revista de Administração (FEAUSP), v. 48, n. 4, p.770-782, out./nov./dez. 2013.

RIBEIRO FILHO, José Francisco; CAMPELO, Sebastião Marcos; ARAÚJO, Fábio da Silva. Os websites dos tribunais de Contas como instrumentos de accountability: uma análise empírica das informações disponibilizadas..5In: Encontro da Anpad, XXIX, 2005, Brasília, DF. Anais... Rio de Janeiro: Anpad, 2005.

RUEDIGER, Marco Aurélio. Governo eletrônico e democracia - uma análise preliminar dos impactos e potencialidades na gestão pública. Organizações \& Sociedade, v. 9, n. 25, set./dez. 2002. 